Table 3. Cross-over Behaviour OF a CURRENT-Flow Model,

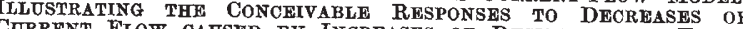
D BY INCREASES OF RESISTANCE AT THREH SITES- $R_{2}, R_{4}$, AND $R_{5}$

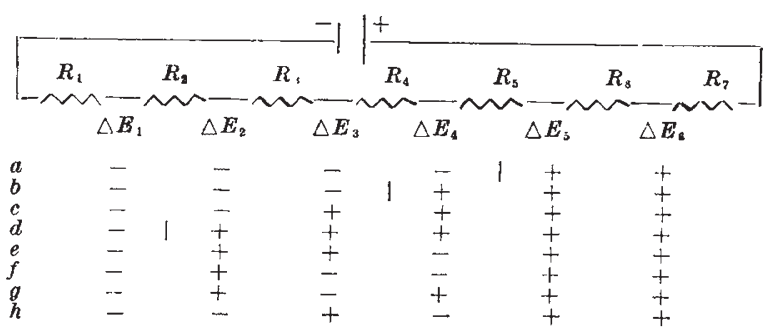

proceeding from $e_{1}$ to $e_{6}$ in response to a decrease of flux or current flow. If one sets down all the conceivable combinations of signs for $\Delta E_{2}, \Delta E_{3}$, and $\Delta E_{4}$ an analysis of the circuit shows rows $a, b, d, e, f$, and $g$ to be realizable with appropriate changes of flux. Thus all three sites of interaction can be readily identified by the - to + cross-over. Rows $c$ and $h$ appear to identify false sites of inhibition, but the analysis further shows that no combination of resistance changes can possibly produce potential changes leading to rows $c$ and $h$. In summary, a - to change associated with a decrease of flux identifies one of the sites at which interaction has occurred.

Neither the current- nor the fluid-flow model represents the bimolecular interaction of electron transfer in the chemical system. The reaction of soluble cytochrome $c$ with the cytochrome $a$ component of a solubilized cytochrome is bimolecular :

$$
c^{\prime \prime}+a^{\prime \prime \prime} \underset{k_{-1}}{\frac{k_{1}}{k_{-1}}} c^{\prime \prime \prime}+a^{\prime \prime}
$$

This reaction holds for lower cytochrome $c$ concentrations, although the reaction at high cytochrome concentrations is complicated by the fact that this substance is inhibitory ${ }^{14}$. No reversibility of the reaction has been demonstrated, that is, $k_{1}>>k_{-1}$. The same rate law holds to a reasonable accuracy ${ }^{22}$ for systems in which the carriers are bound to structures which, in the case of the mitochondria, are probably the cristae. The current-flow model (Holton, F. A., personal communication) appears to represent equation 1 , but $k_{-1}$ must be equal to $k_{1}$, a condition clearly not true for the chemical system. A more general analysis shows that the current-flow system represents, in addition to the reversible system of equal forward and reverse velocity constants, an irreversible system with a rate constant equal to the reciprocal of the sum of all the resistances.

The kinetic response of the current- and fluid-flow models is not representative of equation 1 . While Holton makes no claim that the current-flow model represents chemical kinetics, Lundegårdh does so for the fluid-flow model. The chemical equation for the next step in the reaction is :

$$
a^{\prime \prime}+a_{3}^{\prime \prime \prime} k_{3} a_{3}^{\prime \prime}+a^{\prime \prime \prime}
$$

From equations 1 and 2 , the differential equation for $k_{-1}=0$ has two product terms :

$$
-\frac{\mathrm{d} a^{\prime \prime \prime}}{\mathrm{d} t}=k_{1} c^{\prime \prime} a^{\prime \prime \prime}-k_{3} a^{\prime \prime} a_{3}{ }^{\prime \prime \prime}
$$

As illustrated by this example, and for any mechanism in general, the rates of reactions in a cytochrome system depend on two chemicals, since oxidationreduction reactions are involved. The systems of Lundegårdh and Holton depend on the analogue of only one chemical, and thus differ in a most fundamental way.

This research has been supported in part by a grant from the National Science Foundation. The assistance of Mr. Michael Barr in obtaining the data for Table 2 is gratefully acknowledged.

${ }^{1}$ Chance, B., and Williams, G. R., J. Biol. Chem., 217, 409 (1955). Chance, B., Williams, G. R., Holmes, W. F., and Higgins, J., J. Biol. Chem., 217, 439 (1955).

"Chance, B., and Williams, G. R., "Adv. Enzym.", 17, 65 (1956).

' Singer, T. P., and Kearney, E. B., “Adv. Enzym.”, 15, 79 (1954).

"Mahler, H. A., "Adv. Enzym.", 17, 233 (1956).

"Chance, B., Nature, 169, 215 (1952).

7 Chance, B., and Williams, G. R., J. Biot. Chem, 21\%, 429 (1955).

Bstabrook, R., J. Biol. Chem., 227, 1093 (1957).

- Holmes, W. F. (submitted to Trans. Farad. Soc.)

1) Holton, F., Chem. Weekblad, 53, 207 (1957).

11 Holton, F., Chem. Weekblad (in the press).

${ }^{12}$ Chance, B., and Williams. G. R., J. Biol. Chem, 221, 477 (1956)

${ }^{13}$ Lundegärdh, H., Biochim. Biophys. Acta, 2\%, 653 (1958).

${ }^{14}$ Smith, L., and Conrad, H., Fed. Proc., 17, 313 (1958).

${ }^{16}$ Chance, B., and Baltscheffsky, H., Science, 124, 936 (1956).

${ }^{16}$ Klingenberg, M., Abstract, 4th International Congress of Biochemistry, Vienna, p. 67 (1958).

${ }^{17}$ Chance, B. (in preparation)

${ }^{18}$ Chance, B., and Hess, B. (in preparation).

19 Weber, A., Fed. Proc., 16, 267 (1957).

${ }^{20}$ Jobsis, F. F., and Chance, B., Fed. Proc., 16, 68 (1957).

${ }^{21}$ Ramirez, J., Fed Proc., 17, 128 (1958).

${ }^{22}$ Chance, B., Holmes, W., and Higgins, J., Abstracts, Biophysical Society, Cambridge, p. 45 (1958).

\title{
WATER RESOURCES AND WATER NEEDS IN SCOTLAND
}

\begin{abstract}
A SYMPOSIUM on "Water Resources and Water Needs in Scotland" was held by Section E (Geography) of the British Association on September 1. The following papers were read: "The Need for River Flow Studies", by R. Maclagan Gorrie (Royal Scottish Geographical Society); "Measuring River Flow and Estimating Floods", by P. O. Wolf (University of London); "Evaporation and Land $\mathrm{U}_{\mathrm{s} \theta}$ in Water Conservation Studies", by F. H. W. Green (Nature Conservancy); "Hydro-electric Development in Scotland", by P. L. Aitken (North of Scotland Hydro-electric Board); and "Industry in relation to Water Supply", by L. B. Aitken (Scottish Council Development and Industry).
\end{abstract}

The abundance of pure water has in the past been a major influence in the siting of Scottish developments such as the early linen and cotton mills, paper making, brewing and distilling. It also fixed the sites for aluminium production, and, more recently, for the North of Scotland Hydro-electric Board's sites in Perthshire, Argyll and Ross. The new atomic power stations and chemical factories make very big demands on water supply, so requests for 5 million gallons a day are now common.

The demand for electricity in Scotland is growing by 7 per cent per annum, so that new power stations have to be planned to meet a doubling of output every ten years. The base load which is maintained 
over the whole twenty-four hours can best be met by steam or nuclear stations, but the fluctuations above this minimum are a different matter, and can best be met from steam power or by hydro-electric stations. The peak load may be for only a few hours in each day but will cost three times as much as the base load to produce. Hydro-electric stations of the conventional or of the pumped-storage type are best suited to produce the peak load and can do so at less cost.

Scottish river supplies are thus so valuable that every effort must be made to safeguard them, and the use of this basic resource must be planned. The behaviour of rivers can best be judged from stream-gauge records, but the amount of water reaching a stream-bed is an uncertain fraction of the rain which has fallen within its catchment. To get an accurate picture of the value of a river we must therefore have a knowledge of the rainfall, not only in total but also in intensity, and with enough rain-gauges to provide a grid which will show the pattern of local storms.

Stream-gauging has lagged seriously behind other countries ; in Scotland it was left to private initiative, the pioneer being Capt. W. N. MacClean, who, at his own expense, undertook gauging from 1912 onwards on the Rivers Garry, Moriston, Ness, Lochy and Dee. The data he recorded are of great value, but unfortunately this was not appreciated when he offered them to various Scottish bodies; these records are now being used by the London School of Economics for the training of hydrologists.

The "Surface Water Year Book", now issued officially, covers from 1945 onwards. The Scottish mainland has forty-two major catchments, out of which rainfall-run-off data are presented for sixteen of them or their tributaries. Unfortunately, in the case of two of our most important rivers, the Tay and the Spey, the rainfall data are considered by the Meteorological Office to be inadequate to present rainfall in detail, and the flow of both is affected by transfers of water between the two across their common watershed for hydro-electric supply. Excluding the Tay and Spey, ten catchments of more than a hundred square miles and seven catchments of less than a hundred square miles are recorded, so that their rainfall-run-off ratios can be determined. The readings for all of them for a number of years give a straight-line graph showing a ratio of run-off (A) to rainfall $(R)$ of $A=7 R / 8-8$ (in inches). This differs radically from that given for the Thames basin by E. C. Bilham, in which $A=0.57 R-6.05$ (in inches). This confirms that their behaviour is radically different, as must be expected considering the greater altitude and heavier rainfall of the Scottish Highlands and the very large area of peat which covers them.

Evaporation (including the transpiration from plants) is the largest single item in accounting for the difference between rainfall and run-off. In assessing this loss, two fundamentals have to be separated, namely, the energy causing the evaporation and the water available for the process. By guarantee that water supply is never a limiting factor, we arrive at a figure of 'potential evaporation' which can be considered as a climatic factor comparable with, say, rainfall or air temperature, but to make valid comparisons there must be more or less arbitrarily defined standard conditions.

A grass sward free of obstructions and conforming to the ordinary requirements for a meteorological reporting station has been used by F. H. W. Green,

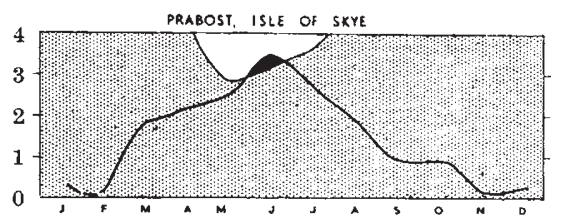

KINLOCHEWE, WESTER ROSS
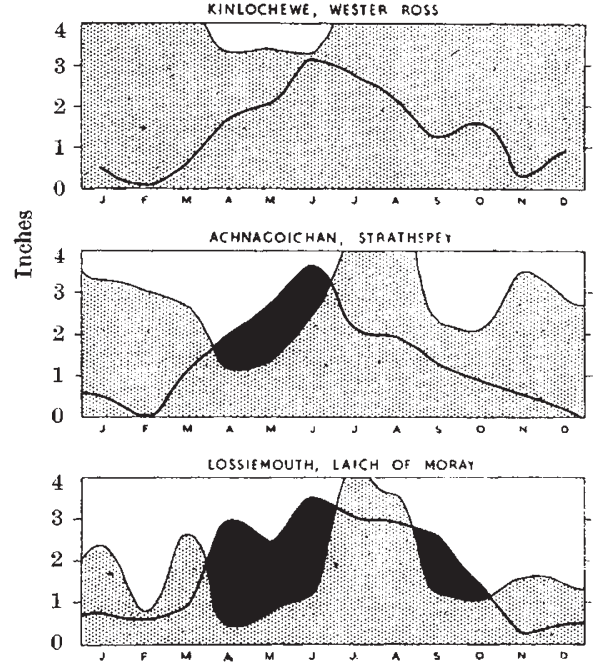

Fig. 1. - - Rainfall ; - - , potential evaporation ; 7 , excess

of the Nature Conservancy staff, in producing valuable contrasts in four Highland readings, as shown in Fig. 1. Kinlochewe is in the maximum rainfall belt, immediately to the west of the main watershed; Prabost in Skye is to the west of this, and Lossiemouth well to the east of it. Achnagoichan in Speyside is intermediate in an intermontane basin but at an elevation of $1,000 \mathrm{ft}$. As the effect of alternative land uses upon the available water supply is the ultimate objective, steps are now being taken to determine the potential evaporation in the centre of a large homogeneous area of spruce.

A historical analysis of damaging floods so far. recorded in Scotland gives the impression that floods and damage occur more frequently at present than they did in the past. When one attempts to analyse this trend in terms of changing land use and run-off conditions, there is already apparent a widespread deterioration in the condition of our moorland peat as a ground cover. This has been brought about bv the moor burning, which has increased in many districts as an answer to the coarsening of the grasses following upon the use of sheep only over a long period of years. When robbed of its protective cover by fire, peat behaves in the same way as any other eroding soil ; in the first heavy rain after the fire it forms a surface slime which seals off the top, thus preventing normal penetration of the rain through the underlying layers of soil and rock to join the water-table. Instead, it all goes off in surface runoff which, of course, increases the 'flashiness' of flood peaks.

Other changes in land conditions which contribute to damaging flood peaks are the increased bank erosion along many of our highland streams, the use of heavy drainage ploughs on sheep-runs and afforestation areas, and the commercial 'skinning' of peat from the bogs for commercial purposes. Flood intensities are clearly a function of the intensities of 
rainfall and of the catchment characteristics, including the limits of retention capacity as influenced by land use and misuse. The hydrological estimate of 'maximum possible floods' or 'probable maximum floods' starts, however, with studies of storm maxima, either by transposing the worst recorded storm for the region on to the catchment in question, or by building up from other meteorological data.

Since the Reservoir (Safety Provisions) Act, 1930, has laid the responsibility for checking the safety of dams upon a panel of engineers, the technique advocated in the Institution of Civil Engineers' Interim Report, 1933, is to plot the peak discharges for all the recorded rivers in Britain in cusecs per thousand acres of catchment for the actual catchment area; the curve thus produced has been of the greatest value as a guide in experienced hands. A revision of this report is now in preparation and will include flood data collected between 1933 and 1957 , and this will be a further step in helping the designers of dams and also those wrestling with flood forecasting.

Local authorities are continually trying to attract new industry to their area, but in many cases do not know what their water resource amounts to. Demands of 5 million gallons a day, or even 20 million, are now met with ; but the number of sites which can cater for such demands is limited, and when the few still to be exploited in England are used up, there will remain only the Scottish Highlands. Unfortunately, we do not know the potential of many Scottish rivers and it is imperative that more data and more reliable data should be collected. Guesses are not good enough; an industrialist will site his factory where he knows there is enough water, and not on another more desirable site where there might be enough.

In the past it has not been the duty of a local authority to measure river flows. It is a highly specialized job and an expensive one if carried out according to the high standards of the Land Drainage Division of the Department of Agriculture for Scotland. The programme of the Division is being greatly extended, but even so, only a fraction of Scottish rivers is now being measured. Under the river purification boards now appointed for eight lowland rivers in Scotland, minimum or nadir flows are being measured, as this is the crucial figure needed to determine permissible pollution. Other county officers, including planners, road engineers and police, want data for safety precautions and flood warning systems, and are adopting various types of gauging less expensive than the Land Drainage Division's specification.

The Royal Scottish Geographical Society has recently established a standing committee for river flow studies and is defraying the expenses of meetings; the group includes the four university geography departments, civil engineers, land drainage and water use specialists, meteorologists and land use planners. The main tasks are to collate flood records, review any research work and encourage fresh efforts in research and survey of river behaviour, and ensure publication of suitable material; to advise local authorities when called upon; and where warranted, to agitate for action on flood control ; to arrange the formation of 'flying squads' for immediate recon. naissance of floods as they occur ; and to encourage longer-term studies bearing upon evapo-transpiration and the ultimate demands on existing water supplies. So far, the committee's main function has been to provide a platform for discussion; the organization is a very long way behind its Danish counterpart, the Hydrology Section of the Danish Heath Society at Slagelse. Hitherto, efforts to get funds have failed and the programme is crippled because of this.

The measurement of the flow of water, starting with surface run-off and finishing in the sea, can properly be considered the sphere of geographers skilled in hydrometry; the basic knowledge must needs include the ecology and geology of the catch. ment as well as the engineering of a gauging site, the best equipment for the given conditions, and the drill for using the instruments properly. Too much of current press writings about floods and water resources shows a superficial approach. It is hoped that this may be counteracted to some extent by getting an increasing number of geographers using a scientific approach and in close collaboration with the engineers to undertake hydrometric work as well as climatological stations, and so build up a fuller knowledge of the nation's water resource.

R. Maclagan Gorrie

\section{NUCLEAR POWER STATIONS}

\section{WORLD PLANS AND EXPERIENCE}

\begin{abstract}
$\mathrm{A}$ $\mathrm{T}$ the first Geneva Conference on the Peaceful Uses of Atomic Energy in 1955 only the U.S.S.R. could claim to have a nuclear power station in operation, and that on little more than an experimental scale. Producing 6,000 kW., it was generally considered, from the description provided, to be no more than a demonstration of feasibility. The building of Calder Hall was well advanced, but it was not in operation and its economy and reliability were still to be demonstrated. The United States, with ample and cheap supplies of fossil fuels, felt less urgency for the development of nuclear power stations and greater difficulty in achieving economic parity with conventional stations at home.

The three years between the first and second Conferences at Geneva have seen very great advances
\end{abstract}

in this field in many countries. The feasibility of nuclear power stations is no longer in question and discussion now centres on the type of reactor to be used, the date by which it will provide electricity as cheaply as conventional stations, in particular national economies, and the rate at which nucleas: power stations can be built. In 1955, only the United Kingdom had a national nuclear power programme, and it is significant of the rate of advancement in this period that within two years this programme had been substantially increased, based on the development potential revealed by the design of the first stations. At the second Conference recently concluded, a number of countries presented papers setting out their plans for the construction of nuclear power stations, not as vague and distant hopes, but 